\title{
Early versus traditional delayed oral feeding after small intestinal and colonic anastomosis
}

\author{
Mahmoud Bahram, MD; Hatem Soltan, MD; Mohamed Ashraf Balbaa, MD
}

Department of General Surgery, Menoufiya University, Egypt.

\begin{abstract}
There is no evidence that bowel rest and a period of starvation are beneficial for healing of wounds and anastomotic integrity of small or large bowel anastomosis. Aim: The aim of this study was to assess early oral feeding compared with the traditional 5 day delay after small intestinal and colonic anastomosis. Patients and methods: The study included 136 patients with either small intestinal or colonic anastomosis randomly divided into two groups 68 patients each. Group I patients were managed traditionally with 5 day delay before oral feeding, while those of Group II were allowed oral fluids once there was audible intestinal sounds and/or passage of faltus. Patients were assessed as regards concomitant diseases, postoperative surgical and medical complications as well as period of hospital stay. Results: There was no statistical significant difference comparing both groups as regards gender and age distribution, cause and type of surgery, the presence of concomitant diseases and occurrence of intestinal fistula or medical complications. There was a significant lower incidence of wound complication $(P=0.032)$ in Group II with significant shorter hospital stay $(P=0.000)$. Conclusion: Early oral feeding after small intestinal and colonic anastomosis is safe, effective, well tolerated and beneficial to the patients.
\end{abstract}

\section{Introduction:}

"To feed or not to feed" is the research question posed by authors in many randomized clinical trials. The traditional postgastrointestinal surgical approach during which an intestinal anastomosis has been formed is to withhold oral intake for several days "nil by mouth". A naso-gastric tube is inserted to decompress the stomach and intravenous fluids are administered. As intestinal dysmotility resolves, postoperative feeding is initiated with gradually increased amounts of fluid. ${ }^{1}$

The rationale of "nil by mouth" is to prevent postoperative nausea and vomiting and to protect the anastomosis, thereafter, allowing time to heal before being stressed by food. ${ }^{2}$ There is no evidence that bowel rest and a period of starvation are beneficial for healing of wounds and anastomotic integrity. Indeed, the evidence is that luminal nutrition may enhance wound healing and increase anastomotic strength, particularly in malnourished patients. ${ }^{3}$ Also patients undergoing surgery are at high risk of nutritional deficiency that can affect their clinical outcome, namely; length of hospital stay, rate of complications and short term mortality. This nutritional deficiency can be caused by increased resting energy expenditure by surgical injury and protein loss, however, the most important contributing factor is the lower intake of these patients immediately after surgery. Therefore, nutritional depletion is considered by many authors as an independent determinant of serious complications after major gastrointestinal surgery. ${ }^{4}$

\section{Aim of the work:}

The aim of this study was to assess early oral feeding compared with the traditional 5 day delay after small intestinal and colonic anastomosis. 


\section{Patients and methods:}

After exclusion of patients with acute obstruction, or intra-abdominal infection, 136 patients that had undergone small intestinal or colonic anastomosis either electively or as an emergency procedure were included. All the patients were admitted to the General Surgery Department at Menoufyia University Hospital in the period from January 2007 to December 2009. After obtaining a clear informed consent, the patients were randomized into two groups; 68 patients each by computer-generated random allocation software. (Group I) patients were managed traditionally by naso-gastric insertion till audible intestinal sounds and keeping them nil per mouth till the 5th day. On the 6th day, patients started oral fluids only and on the 7th day started semi-solids then solid food on the 8th day. Patients were discharged on the 9th day, if no complications. On the other hand, patients in (Group II) were managed with no naso-gastric tube insertion, all patients received early oral feeding in the form of oral fluids once there was audible intestinal sounds and/or passage of faltus, then solids on the next day unless there were complications as fistula or ileus.

Patients were assessed as regards presence of concomitant cardiovascular or pulmonary diseases, preoperative random blood sugar and serum albumin, postoperative surgical complications as (wound infection, anastomotic leak, intra-abdominal abscess, bowel obstruction), postoperative non surgical complication as cardiovascular and pulmonary complications, primary hospital stay and readmission rate.

Statistical analysis was performed using Chi square test for qualitative parameters and Student " $t$ " test for quantitative parameters using SPSS-17 (Statistical Package for Social Sciences version 17). Probability values of less than 0.05 were considered significant.

\section{Results:}

Group I included 38 males and 30 females. Their ages ranged from 12 to 67 years with a mean of $40.49 \pm 14.91$ years, while Group II included 41 males and 27 females and their ages ranged from 19 to 72 years with a mean of $38.03 \pm 13.39$ years. There were no statistical significant differences comparing the two groups as regards age and gender distribution $(\mathrm{P}=0.314$ and 0.602 respectively). Table(1) shows the distribution and type of resection, of both small intestinal and colonic cases in both groups, while Table(2) shows the underlying cause of surgical interference in both groups with no statistical significant difference comparing the two groups.

Cardiovascular diseases were found concomitantly in $12(17.65 \%)$ patients in Group I and in $8(11.76 \%)$ patients in Group II $(\mathrm{P}=0.333)$, while chronic pulmonary disease were found in $5(7.35 \%)$ and $4(5.88 \%)$ patients in Group I and II respectively $(\mathrm{P}=0.730)$. Twelve patients (17.65\%) of Group I, and 15 patients $(22.05 \%)$ of Group II complained of diabetes mellitus $(\mathrm{P}=0.519)$, while hypoalbuminea (defined as serum albumin < $3.5 \mathrm{~g} / \mathrm{dl}$ ) were found in 7 patients $(10.29 \%), 5$ patients $(7.35 \%)$ in Group I and Group II respectively with no statistical significant difference between the two groups $(\mathrm{P}=0.545)$, as shown in Table(3).

Two patients (2.94\%) in Group I and 3 patients in Group II $(4.41 \%)$ were complicated with intestinal fistula with no significant statistical difference between the two groups $(\mathrm{P}=0.649)$. One patient in each group had low output small intestinal fistula, which was managed conservatively by naso-gastric tube insertion and total parentral nutrition regimen. One patient in each group had colonic fistula, which was managed by proximal defunctioning colostomy. The 3rd case in Group II was high output small intestinal fistula that was managed by re-exploration where revision of the partially dehisced anastomosis was done. As shown in Table(4), nasogastric tube was used in a significantly lower number of patients in Group II (3 patients) while it has been used in all the patients of Group I and reinserted again in 2 patients $(\mathrm{P}=0.000)$.

As shown in Table(5), wound complications were significantly higher in group I than Group II $(\mathrm{P}=0.032)$. Although medical complications occurred with a higher percentage in Group I $(16.17 \%)$ than in Group II (5.88\%), still there were no statistical significant difference $(\mathrm{P}=0.200)$ between the two groups, as shown in Table(6). 
As regards hospital stay, it ranged from 829 days in Group I with a mean of $15.46 \pm 6.53$, which was significantly longer than in Group
II, that ranged from 3-24 days with a mean of 9.54 $\pm 5.32(\mathrm{P}=0.000)$.

Table (1): Distribution of both small intestinal and colonic cases and type of resection in colonic cases.

\begin{tabular}{|c|c|c|c|c|c|}
\hline & Total Number & Group I & Group II & $P$ value \\
\hline \multicolumn{2}{|c|}{ Small intestinal } & 42 & 23 & 19 & 0.458 \\
\hline \multirow{5}{*}{$\begin{array}{l}\text { Colonic } \\
\text { (94 cases) }\end{array}$} & Right hemicolectomy & 21 & 9 & 12 & 0.477 \\
\hline & Transverse colectomy & 8 & 4 & 4 & 1.000 \\
\hline & Left hemicolectomy & 24 & 13 & 11 & 0.653 \\
\hline & Sigmoidectomy & 34 & 15 & 19 & 0.428 \\
\hline & Low anterior resection & 7 & 4 & 3 & 0.698 \\
\hline \multicolumn{2}{|r|}{ Total } & 136 & 68 & 68 & \\
\hline
\end{tabular}

Table (2): Underlying cause of surgical interference.

\begin{tabular}{|c|c|c|c|c|}
\hline Underling Disease & Total Number & Group I & Group II & P value \\
\hline Malignancy & 101 & 53 & 48 & 0.428 \\
\hline Recurrent volvulus & 7 & 3 & 4 & 0.698 \\
\hline Secondary intussusceptions & 2 & 1 & 1 & 1.000 \\
\hline Colonic polyp & 9 & 4 & 5 & 0.730 \\
\hline Trauma & 17 & 7 & 10 & 0.437 \\
\hline Total & $\mathbf{1 3 6}$ & $\mathbf{6 8}$ & $\mathbf{6 8}$ & \\
\hline
\end{tabular}

Table (3): The concomitant diseases.

\begin{tabular}{|l|c|c|c|c|c|c|}
\hline \multirow{2}{*}{ Concomitant Diseases } & \multirow{2}{*}{$\begin{array}{c}\text { Total } \\
\text { Number }\end{array}$} & \multicolumn{2}{|c|}{ Group I } & \multicolumn{2}{|c|}{ Group II } & P value \\
\cline { 3 - 7 } & & No. & \% & No. & \% & \\
\hline Cardiovascular diseases & 20 & 12 & $17.65 \%$ & 8 & $11.76 \%$ & 0.333 \\
\hline Chronic pulmonary diseases & 9 & 5 & $7.35 \%$ & 4 & $5.88 \%$ & 0.730 \\
\hline Diabetes & 27 & 12 & $17.65 \%$ & 15 & $22.05 \%$ & 0.519 \\
\hline Hypoalbuminemia & 12 & 7 & $10.29 \%$ & 5 & $7.35 \%$ & 0.545 \\
\hline \multicolumn{1}{c|}{ Total } & $\mathbf{1 3 6}$ & $\mathbf{6 8}$ & & $\mathbf{6 8}$ & & \\
\hline
\end{tabular}


Table (4): Fistula and nasogastric tube insertion.

\begin{tabular}{|l|c|c|c|c|c|}
\hline \multirow{2}{*}{} & \multicolumn{2}{|c|}{ Group I } & \multicolumn{2}{c|}{ Group II } & P value \\
\cline { 2 - 6 } & No. & $\%$ & No. & \% & \\
\hline Fistula & 2 & $2.94 \%$ & 3 & $4.41 \%$ & 0.649 \\
\hline Nasogastric tube insertion & 68 & $100 \%$ & 3 & $4.41 \%$ & $0.000^{*}$ \\
\hline
\end{tabular}

Table (5): Wound complications.

\begin{tabular}{|l|c|c|c|c|c|}
\hline \multirow{2}{*}{} & \multicolumn{2}{|c|}{ Group I } & \multicolumn{2}{c|}{ Group II } & P value \\
\cline { 2 - 6 } & No. & \% & No. & \% & \\
\hline Bleeding and heamatoma & 3 & $4.41 \%$ & 1 & $1.47 \%$ & 0.310 \\
\hline Minor wound infection & 9 & $13.23 \%$ & 3 & $4.41 \%$ & 0.070 \\
\hline Severe wound infection & 7 & $10.29 \%$ & 2 & $2.94 \%$ & 0.085 \\
\hline Complete Wound dehiscence & 5 & $7.35 \%$ & 2 & $2.94 \%$ & 0.244 \\
\hline Total & $\mathbf{2 4}$ & $\mathbf{3 5 . 2 9 \%}$ & $\mathbf{8}$ & $\mathbf{1 1 . 7 6 \%}$ & $\mathbf{0 . 0 3 2}$ \\
\hline
\end{tabular}

Table (6): Medical complications.

\begin{tabular}{|c|c|c|c|c|c|}
\hline \multirow{2}{*}{} & \multicolumn{2}{|c|}{ Group I } & \multicolumn{2}{c|}{ Group II } & P value \\
\cline { 2 - 6 } & No. & \% & No. & \% & \\
\hline Cardio-vascular & 2 & $2.94 \%$ & 1 & $0.68 \%$ & 0.559 \\
\hline Pulmonary & 7 & $10.29 \%$ & 2 & $2.94 \%$ & 0.085 \\
\hline D.V.T & 3 & $4.41 \%$ & 1 & $0.68 \%$ & 0.310 \\
\hline Total & $\mathbf{1 2}$ & $\mathbf{1 6 . 1 7 \%}$ & $\mathbf{4}$ & $\mathbf{5 . 8 8 \%}$ & $\mathbf{0 . 2 0 0}$ \\
\hline
\end{tabular}

\section{Discussion:}

Recent efforts to achieve standard perioperative care protocols for patients undergoing small intestinal and colonic surgery have reduced the postoperative hospital stay to 2 to 3 days, compared with the usual 6 to 10 days. Revision of the postoperative care program has occurred in response to recent scientific data demonstrating that routine use of nasogastric tubes is not indicated and that early oral feeding may be instituted without risk. ${ }^{5}$

Silk and Gow ${ }^{4}$ have concluded in their study that supplementing "normal" oral diet in hospital wards with as little as $300 \mathrm{kcal}$, and $12 \mathrm{~g}$ of protein per day resulted in a reduction of postoperative complications in patients undergoing gastrointestinal surgery. Marik and Zaloga ${ }^{6}$ conducted meta-analysis of prospective randomized studies comparing early versus late enteral feeding and demonstrate the benefits of early nutrition. Seenu and $\mathrm{Goel}^{7}$ in their study, showed that early oral feeding after elective colorectal surgery is safe and can be tolerated by most patients. Similarly, Difronzo et $\mathrm{al}^{8}$ demonstrated a high tolerability $(86.5 \%)$ to early postoperative oral feeding after elective open colon resection. Andersen and colleagues ${ }^{9}$ conducted a systematic review of 13 randomized trials totaling 1173 patients undergoing gastrointestinal surgery. There were no significant differences between restricted and early postoperative diets, but the findings also suggested that there was no advantage to dietary restriction. In the current study, early feeding was started in Group II patients and oral feeding was tolerated with low morbidity 
following small or large bowel resections and was not associated with the occurrence of significant increase in anastomotic dehiscence.

The colonic enterocyte is dependent on the colonic lumen for the vast majority of its energy supply (up to about $85 \%$ ) and probably cannot compensate by obtaining large amounts of food from the bloodstream. This is because it obtains its energy from butyric acid, which is derived from bacterial digestion of fiber. If fiber is not provided, the colonic enterocytes are not fed adequately. More than 1000 billion bacteria within the body are largely found in the colon. Colonic enterocytes are systematically malnourished followed by disturbance of the normal flora with broadspectrum antibiotic therapy. ${ }^{4}$ Within 24 hours of starvation, changes in metabolism are evident including increased insulin resistance and reduced muscle function. Experimental data from both humans and animals shows evidence that providing nutrition in the immediate postoperative period improves wound healing (relevant to the integrity of the intestinal anastomosis), muscle function, insulin resistance and reduces sepsis. ${ }^{10}$ In the current study post operative wound complication were significantly lower in Group II than Group I patients.

A significant relative reduction in the risk of infection of any type was observed for patients receiving early enteral nutrition. Changes in intestinal permeability have been shown in patients undergoing gastrointestinal surgery, increased permeability being associated with sepsis and systemic inflammation. Bacterial translocation has also been shown in patients undergoing laparotomy, and a higher proportion of patients with bacterial translocation developed sepsis than those without. Early postoperative luminal nutrition might have a beneficial effect on the function of the intestinal barrier in respect of permeability, bacterial translocation, and the subsequent development of septic complications. ${ }^{11}$

In the current study, there was a higher percentage of medical complication in Group I although it did not reach a statistical significant difference between the two groups. This can be due to the significant higher rate of nasogastric tube insertion and the significant longer hospital stay with consequent delayed ambulation and longer period of bed recumbency.

The benefit of postoperative enteral feeding in surgical patients is that it reduces nutritional deficit that predisposes patients to developing complications, including deficits in muscle function and surgical fatigue. Early oral feeding can preserve body organ functions rather than the usual postoperative deterioration in pulmonary function, body composition, and cardiovascular response to exercise. ${ }^{12}$

\section{Conclusion:}

It is concluded that early oral feeding after small intestinal and colonic anastomosis is safe, effective and beneficial to the patients as it is well tolerated, does not increase the risk of anastomotic leakage and helps in decreasing wound infection and improve wound healing leading to short hospital stay. However, larger, prospective and randomized trials are needed to establish the facts observed in the present as well as previous similar studies.

\section{References:}

1- Han-Geurts IJ, Hop WC, Kok NF, Lim A, Brouwer KJ, Jeekel J: Randomized clinical trial of the impact of early enteral feeding on postoperative ileus and recovery. $\mathrm{Br} \mathrm{J}$ Surg 2007; 94(5): 555-561.

2- Lewis SJ, Egger M, Sylvester PA, Thomas $S$ : Early enteral feeding versus "nil by mouth" after gastrointestinal surgery: Systematic review and meta-analysis of controlled trials. BMJ 2001; 323(7316): 773-776.

3- Malhotra A, Mathur AK, Gupta S: Early enteral nutrition after surgical treatment of gut perforations: A prospective randomised study. J Postgrad Med 2004; 50(2): 102106.

4- Silk DB, Gow NM: Postoperative starvation after gastrointestinal surgery. Early feeding is beneficial. BMJ 2001; 323(7316): 761762.

5- Kehlet H, Wilmore DW: Multimodal strategies to improve surgical outcome. Am J Surg 2002; 183(6): 630-641. 
6- Marik PE, Zaloga GP: Early enteral nutrition in acutely ill patients: A systematic review. Crit Care Med 2001; 29(12): 2264-2270.

7- Seenu V, Goel AK: Early oral feeding after elective colorectal surgery: Is it safe? Trop Gastroenterol 1995;16(4): 72-73.

8- DiFronzo LA, Yamin N, Patel K, O'Connell TX: Benefits of early feeding and early hospital discharge in elderly patients undergoing open colon resection. $J \mathrm{Am}$ Coll Surg 2003; 197(5): 747-752.

9- Andersen HK, Lewis SJ, Thomas S: Early enteral nutrition within $24 \mathrm{~h}$ of colorectal surgery versus later commencement of feeding for postoperative complications. Cochrane Database Syst Rev 2006(4): CD004080.
10-Lewis SJ, Andersen HK, Thomas S: Early enteral nutrition within $24 \mathrm{~h}$ of intestinal surgery versus later commencement of feeding: A systematic review and metaanalysis. J Gastrointest Surg 2009; 13(3): 569-575.

11-O'Boyle CJ, MacFie J, Mitchell CJ, Johnstone D, Sagar PM, Sedman PC: Microbiology of bacterial translocation in humans. Gut 1998; 42(1): 29-35.

12-Basse L, Thorbol JE, Lossl K, Kehlet H: Colonic surgery with accelerated rehabilitation or conventional care. Dis Colon Rectum 2004;47(3): 271-277. 